\title{
Interações bióticas e abióticas no nordeste do Pará
} Biotic and abiotic interactions in northeastern Pará

\author{
Maria de Lourdes Pinheiro Ruivo \\ Museu Paraense Emílio Goeldi/MCTIC \\ Rogério Rosa da Silva \\ Museu Paraense Emílio Goeldi/MCTIC
}

O Programa de Grande Escala da Biosfera-Atmosfera da Amazônia (LBA), vinculado ao Ministério de Ciência, Tecnologia, Inovações e Comunicações (MCTIC), tem como objetivo estudar o funcionamento e a interação entre todos os componentes do ecossistema amazônico - atmosfera, solos, rios, flora, fauna e seres humanos - em sistemas de terra firme e costeiros. O Núcleo LBA Belém desenvolve pesquisa em vários sítios no estado do Pará (Santarém, Caxiuanã, Cuiarana), o que contempla a participação de pesquisadores de diversas instituições de pesquisa e ensino do estado do Pará, entre as quais constam o Museu Paraense Emílio Goeldi (MPEG), a Universidade Federal do Pará (UFPA), a Universidade Federal do Oeste do Pará (UFOPA) e a Empresa Brasileira de Pesquisa Agropecuária (EMBRAPA). Implantada em 1999, a primeira fase do programa LBA contou com financiamento da Fundação de Pesquisa do Estado de São Paulo (FAPESP), do Conselho Nacional de Desenvolvimento Científico e Tecnológico (CNPq), da National Aeronautics and Space Administration (NASA) e da comunidade europeia.

A segunda fase do programa LBA tem como prioridade a aplicação dos resultados das pesquisas científicas referentes ao desenvolvimento sustentável da Amazônia. Com isso, o plano científico consolidou as sete áreas iniciais de estudo do programa em três grandes áreas integradas: a interação biosfera-atmosfera, o ciclo hidrológico e as dimensões sociopolíticas e econômicas das mudanças ambientais. Atualmente, o escritório local da regional Belém está sediado no MPEG, que também é responsável científicamente e admistrativamente por um dos mais importantes sítios de pesquisa de longa duração do Brasil e do programa LBA, a Estação Científica Ferreira Penna (Caxiuanã), onde são realizadas pesquisas em diversas áreas do conhecimento, incluindo temas de programas de pesquisa do MCTIC.

No âmbito do LBA, dois importantes e recentes projetos fazem parte do portifólio dos estudos climáticos na Amazônia, desenvolvidos no estado: 1) Programa de Apoio a Núcleos de Excelência (PRONEX) - "Mudanças climáticas/ Rede de mudanças climáticas e ambientais do Pará: uma perspectiva de estudos integrados", financiado pelo CNPq/ FAPESPA; e 2) "Implicações da deficiência hídrica no solo e alterações micrometeorológicas sobre a dinâmica florestal e ciclo de carbono em uma floresta tropical chuvosa na Amazônia brasileira", financiado pelo Edital CNPq/LBA. Ambos reúnem grupos de pesquisa nas áreas de Ciências Ambientais, Ciências Agrárias e Geociências, com mais de dez anos de atuação no estado do Pará. Alguns pesquisadores foram formados dentro do programa LBA, vinculados à iniciação científica e à pós-graduação, o que envolveu treinamento, capacitação e a participação de instituições do Brasil e do exterior.

Assim, a presente edição especial do Boletim do Museu Paraense Emílio Goeldi. Ciências Naturais, com o título "Interações bióticas e abióticas no nordeste do Pará", apresenta seis contribuições científicas, envolvendo ampla diversidade de temas, incluindo discussões sobre ecossistemas de terra firme e litorâneos no estado do Pará. Estudos em floresta de terra firme foram desenvolvidos especialmente na Estação Científica Ferreira Pena, considerada como o principal sítio do

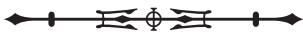


programa LBA na Amazônia oriental. Neste sítio, está instalado o Experimento de Seca na Floresta Amazônica (ESECAFLOR), com estudos feitos a longo prazo sobre o efeito da exclusão de água na floresta (estresse hídrico).

Estudos envolvendo a área litorânea do estado estão representados, nesta edição, por uma pesquisa sobre a circulação de brisas e a precipitação no litoral paraense, na qual Germano e colaboradores apontam que as circulações de brisas marítima-terrestre influenciam a precipitação no litoral paraense. Por outro lado, Berredo e colaboradores avaliam as modificações nas propriedades físico-químicas de sedimentos de manguezais em relação ao clima amazônico, indicando que variações de gradientes físico-químicos estão intimamente associadas com o clima, os ciclos das marés e a circulação das águas intersticiais; em conjunto, determinam o grau de desenvolvimento e a diferenciação vertical e lateral dos sedimentos, bem como a distribuição da vegetação no estuário.

Os artigos desenvolvidos no experimento ESECAFLOR, em Caxiuanã, mostram como se comportará o bioma amazônico, caso seja submetido a um evento extremo e prolongado. Em termos de fertilidade de solos, Guerreiro e colaboradores mostram que as diferenças entre as parcelas de estudo no ESECAFLOR podem estar relacionadas aos efeitos da disponibilidade na variação sazonal dos atributos químicos de latossolos. A área experimental com seca induzida apresentou as menores concentrações para a maioria dos nutrientes avaliados, evidenciando a influência do processo de exclusão das águas pluviais na disponibilidade dos elementos no solo.

Avaliações relacionadas à influência do estresse hídrico sobre a decomposição da serapilheira, desenvolvidas por Castro e colaboradores, mostraram que a deficiência de água interfere no processo de decomposção do material, o que afeta o mecanismo de decomposição das folhas. Em termos de comunidades vegetais, Ferreira e colaboradores revelam profundos impactos do estrese hídrico, independentemente da estação do ano, sobre a estrutura taxonômica de assembleias de plantas jovens.

Por meio de estudos climáticos envolvendo a quantificação das variações mensais e horárias de elementos meteorológicos em ecossistema florestal, feitos no período de 2005 a 2013 por Costa e colaboradores, foi possível obter uma descrição básica dos mecanismos físicos que controlam a dinâmica do tempo sazonal nas florestas tropicais.

O presente número especial, envolvendo pesquisadores de diferentes instituições do estado do Pará, consolida o programa LBA na Amazônia oriental, apresentando pesquisas e resultados de alto impacto para a compreensão do funcionamento e da preservação do bioma amazônico, os quais podem ser usados em políticas públicas. Dessa forma, o programa atinge também um papel importante, contribuindo de forma objetiva para a conservação e o aproveitamento sustentável da biodiversidade amazônica.

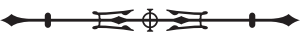

